\title{
The Influence of HIV-AIDS Public Enlightenment Campaigns on Adolescents Sexual Behavior in Nigeria
}

\author{
Adekunle. A. Adegoke \\ Department of Psychology, Obafemi Awolowo University, Ife, Nigeria \\ John. E. Fife \\ Department of Psychology, Virginia State University \\ Zaccheus Ogunnika \\ Department of Sociology, Virginia State University \\ Melissa L. Heemer \\ Department of Psychology, Virginia State University
}

\section{Doi:10.5901/jesr.2014.v4n6p199}

\section{Abstract}

This paper assessed the influence of HIVIAIDS public enlightenment campaigns on adolescents' sexual behavior and their knowledge, attitudes and beliefs about HIV/AIDS. Data generated from a survey conducted among 1902 (917 males and 985 females) adolescent students in Ibadan Nigeria were analyzed using SPSS at the .05 level of significance. The obtained results revealed that adolescents have been exposed to a variety of HIVIAIDS campaigns. The broadcast media (television and radio) exerted more significant influence on adolescents' sexual behaviors, while the print media exerted greater influence on their knowledge, attitudes and beliefs about HIV/AIDS. Also, adolescents' knowledge, attitude and beliefs about HIV/AIDS had significant positive influence on their sexual behaviors.

Keywords: HIV/AIDS, adolescents, sexual behavior, campaign

\section{The Influence of HIV-AIDS Public Enlightenment Campaigns on Adolescents Sexual Behavior in Nigeria}

Throughout history, human beings have been faced with disastrous catastrophes which must be endured in order to survive. Acquired Immune Deficiency Syndrome (AIDS) caused by the Human Immunodeficiency Virus (HIV) remains one of the most incomprehensible disasters for humanity. An estimated number of people living with HIV stood at over 33.3 million at the end of year 2007. Of this figure, 22.5 million are from Sub-Saharan Africa, the region with most affected victims in the global AIDS epidemic. More than three quarters (76\%) of all AIDS deaths in 2007 came from Africa, with another 1.7 million cases of newly infected people. (UNAIDS/WHO, 2008).

The last two decades have witnessed quantum of research work on issue on HIVIAIDS. Scientific literature is full of materials with diverse research interests. In the early years of the detection of the disease, some scientists focused on laboratory studies, examining the causative pathogens and conditions associated with human pathological transmission and various sources of agents and routes responsible for the transmission. A significant proportion of researchers have worked on possible solution to the infectious disease, addressing the possibility of developing a vaccine that can be used for inoculation or drug to cure already infected individuals. This has met with little success. Researchers in the social sciences have concentrated on the implications of the disease on the society. Particular emphasis has been on the behavioral adjuncts associated with the disease.

Prominent in this endeavour is the examination of life style of the so-called "risk groups" and other behavioral factors predisposing individuals to contracting the disease. Men having Sex with Men (MSM), Prostitutes, Commercial Sex Workers, (CSW) and Intravenous Drug Users (IDUs) were the first target risk groups identified for HIVIAIDS. Emphasis has gradually been shifted to the populace at large, having noted that it is not individuals labelled as "at risk" but one's lifestyle constitutes a major determinant factor in HIVIAIDS prevention. 
Generally, it is believed that the media is a powerful and influential means of educating the public on many topics and issues, especially AIDS. It is the most common source of information for youths, because of its entertainment value as well as its accessibility and low costs. HIVIAIDS information from radio and television in form of advertisements, news, and live show constitutes the major ways through which adolescents gain HIV information. Many research findings are continually been published in this direction, with the hope that a successful prevention programs will checkmate the populace against indiscriminate sexual behavior, adopt safe sex practices and internalize AIDS risk reduction behaviors. In order to achieve this goal, government of various nations and other stakeholders which included international bodies and donors agencies have supported and implement a number of enlightenment programs worldwide. In Nigeria, there are weekly radio programs designed to disseminate family planning, HIVIAIDS, and other reproductive health information sponsored by the VISION Project (Keating, et al, 2006). Society for Family Health had also sponsored different radio drama aimed at increasing awareness of HIVIAIDS. Included in these series are "one thing at a time," Garin Muna Fata (Town of Hope), Odenijii, and "Abule Oloke Merin." There were other television, radio, printed materials and organized outreach programs (lecture, seminar, workshop, peer led education) geared towards educating the populous about the menace of HIVIAIDS and attendant consequences associated with unprotected sex. The ultimate goal is to achieve drastic reduction in the prevalence rate of 3-6\% of adult population. A number of studies have documented a substantial positive impact of HIVIAIDS prevention programs (Medley, Kennedy, O'Reilly, \& Sweat, 2009; Kurth, Celum, Baeten, Vermund, \& Wasserheit, 2011; Kirby, Laris, \& Rolleri, 2009; Myers et al, 2010; Marshall, Crepaz, \& O'Leary, 2010). Although a substantial number of the reviewed studies converge on the positive impact of education/enlightenment campaigns on prevention programs, there are few divergent views on the most effective method. While Li et al. (2010), observed that in programs attempting to bring about behavior change among adolescents, peer-led health education has been demonstrated to be an effective method of programme delivery. Studies conducted by Wakefield, Loken, \& Hornik (2010) and Anema et al. (2010) considered media campaigns as the best way to educate young people about the disease and condom use.

Adolescents, by virtue of a number of behavioral and social characteristics, are more at risk in contracting HIV infection than any other development groups. Of many factors which predispose them to high risk include the early onset of sexual activity during the teen years (Ma, 2009; Sandfort, Orr, Hirsch, \& Santelli, 2008; Hallet, 2007); the probability of multiple partnerships (Shelton, 2009; Kalichman et al., 2007); general non use or inconsistent use of condoms (Cherutich, Brentlinger, Nduati, Kiarie, \& Farquhar, 2008); and the reported tendency of adolescents to perceive themselves to both physically and psychologically invulnerable which in turn is related to the conduct of a variety of risk behaviors (Menser, 2010). Robbins et al., (2010) noted that in areas of high HIV seroprevalence, infection will most likely occur in adolescence with early sexual exposure and therefore suggests that programs must educate adolescents about the risk involved with specific behavior and how to reduce those risks.

The objective of this study is to assess the influence of HIVIAIDS enlightenment campaigns on adolescents' sexual behaviour practices and their knowledge, attitudes and beliefs about HIVIAIDS. Adolescents have become a focal point on discussions of sexuality and reproductive health matters, because they belong to a most active segment of the population and because of practical concerns on resolving problems such as unintended pregnancy and sexually transmitted diseases (STDs), including HIVIAIDS (Jemmott, 2012). Three hypotheses were formulated for this study. The first hypothesis stated that HIVIAIDS enlightenment campaign programs disseminated through broadcast media will have more significant positive influence on adolescents' sexual behaviors than those disseminated through print media and organized activities. Hypothesis two stated that HIVIAIDS enlightenment campaign programs disseminated through broadcast media will have more significant influence on adolescents' knowledge, attitudes and beliefs (KAB) about HIVIAIDS than those disseminated through print media and organized activities. The third hypothesis examines the influence of adolescents' exposure to enlightenment campaigns on their sexual behavior, with the aim that those highly exposed will have lower sexual risk behaviors than those with lower exposure.

\section{Method}

\subsection{Sample}

The sample consisted of 1902 adolescents from 20 schools in five local governments of Ibadan, Nigeria, ranging in age from 12-20. Of these, there were 917 (48.2\%) males and 985 (51.8\%) females. A mean of 16 years and standard deviation of 1.46 was obtained for the respondents' age. The students selected were stratified using their sex, age, class and local government. This was done in order to have an unbiased and representative sample. Four secondary schools 
from each of the five local governments participated in the study. The sample comprised students from both single sex and mixed schools. Twelve mixed and eight single sex (4 only boys and 4 girls only) schools participated in the study, and 825 students came from single sex schools while the majority (1077) came from mixed schools.

\subsection{Measures}

Two instruments were used in the study. They consisted of self-administered paper -and- pencil questionnaire whose items were purposely adapted for this study. The majority of the instrument items were generated through an extensive adaptation of Haour-knipe. Fleury and Dubois- Arber (1999); LeBlanc (2000) and Adamchak, Bond, MacLaren, Magnani, Nelson and Seltzer (2002) questionnaires used in previous studies of a similar nature.

The questionnaire, which was comprised of mostly structured close-ended items, was divided into three sections. The first section sought for socio-demographic information from each respondent. The second section addressed the sources of HIVIAIDS awareness campaigns exposed to and perceived influence of these programs on adolescent behavior. Section three of the questionnaire focused on adolescents' sexual behavior practices, which included; current sexual activities, number of sexual partners, condom use, frequency and rate of sexual intercourse and reasons for engaging in sexual activities.

\section{Procedures}

Data were collected from all the selected school students using the prepared paper and pencil, self-report questionnaire. Principals and school counsellors of the selected 20 schools in Ibadan metropolis were contacted through personal letters from the researcher before the administration of the questionnaire for their consent and cooperation.

Fifty students from the Psychology and Philosophy departments at Obafemi Awolowo University served as field assistants for the study. Ten of these students were used as coordinators for the five local government areas, monitoring the activities of other students sent to the selected schools. Two students were sent to each of the selected twenty schools with the pack of questionnaire meant for the selected students. The data collection was done in each school with the assistance of school counselor in that school and other designated teacher/officer by the Principal/Vice Principal. For ease of administration, the students drawn from each of the classes were pooled together in a quiet area within the school premises. Instructions on how to complete the questionnaire, which had been printed on the questionnaire, were read to the group of selected adolescents by the field assistants. The completed questionnaires were collected at the end of a specified period, which ranged between 20 and 25 minutes.

\section{Results}

Multiple regression analysis was used to test if HIVIAIDS enlightenment campaign programs disseminated through broadcast media have a more positive influence on adolescents' sexual behavior than those disseminated through print media and organized activities. Adolescents' scores on three types of exposure to enlightenment campaigns and their sexual behaviours were used in the analysis.

Results in Table 1 indicate that there is a significant low relationship between the three types of exposure to enlightenment campaigns and sexual behaviors $(R=0.227)$. The regression equation with all the three predictors is significantly related to the sexual behaviors of adolescents $\left(F_{3,1897}=34.483, p<0.0001\right)$; Describing $5.2 \%$ of the variance in sexual behavior $\left(R^{2}\right.$ adj $\left.=5.0 \%\right)$. R-square, which shows the joint contribution of the independent variables (broadcast media, print media and organized activities) to the dependent variable (sexual behavior), indicated that these independent variables jointly contribute $5.2 \%$ of the variance in sexual behavior $\left(R^{2}\right.$ adj $\left.=5.0 \%\right)$.

When examined for the best overall predictor, broadcast media was found to contribute most to the variance observed in sexual behavior, $\beta=0.217$; $t=8.769, p<0.0001$, compared with print media, $\beta=0.120, t=-4.980, p<$ 0.001 , and organised activities, $\beta-0.056, t=2.310, p<0.021$. Further observation revealed that of the five percent variance obtained, broadcast media accounted for 3.8\% $\left(R=0.96, R^{2}=-.038, F_{1,1899}=75.727, p<0.0001\right)$, while broadcast media and print media jointly contributed $4.8 \%$ of the variance $\left(R=0.221, R^{2}=0.049, F_{2,1898}=48.945, p<\right.$ 0.0001 . This means that HIVIAIDS enlightenment campaigns disseminated through broadcast media have more significant positive influence on adolescents' sexual behaviours than those disseminated through print media and organized activities. The hypothesis was therefore confirmed.

Hypothesis 2 stated that HIVIAIDS enlightenment campaign programs disseminated through broadcast media will 
have more significant influence on adolescents' knowledge, attitudes and beliefs (KAB) about HIVIAIDS than those disseminated through print media and organized activities. The result of multiple regression analysis conducted to evaluate how broadcast media predicted adolescents' knowledge, attitudes and beliefs (KAB) about HIVIAIDS over the print media and organized activities is presented in Table 2.

The results indicate a significant linear combination of print media and broadcast media on adolescents' knowledge, attitudes and beliefs (KAB) about HIVAIDS $\left(F_{2,1898}=53.963, p<0.0001\right)$. Organised activities had no significant influence on knowledge, attitudes and beliefs about HIVI AIDS $(r=0.007, p \geq 0.387, t=-1.381, p>0.168)$; hence it was excluded from the stepwise regression analysis $(p>0.05)$. The sample multiple correlation coefficient $\left(R^{2}=\right.$ 0.232 ) indicated that approximately $5.4 \%$ of the variance of adolescents' knowledge, attitudes and beliefs about HIVIAIDS can be accounted for by the linear combination of broadcast and print media.

There was a significant relationship between print media and knowledge and the attitudes and beliefs of participants $(r=0.212, p<0.0001)$, as well as between broadcast media and knowledge, attitudes and beliefs scores $(r=$ $-0.181, p<0.001)$. On examination for the best overall predictor, print media was found to contribute more to the variance observed in knowledge, attitudes and beliefs (KAB) about HIVIAIDS $(\beta=0.246, t=10.358, p<0.0001)$ than broad cast media ( $\beta=-0.100, t=-4.233, p<0.0001$ ). It was further observed that out of the $5.3 \%$ variance in adolescents' knowledge, attitudes and beliefs (KAB) about HIVIAIDS, print media accounted for $4.5 \%\left(R=0.212, R^{2}=\right.$ $\left.0.45, F_{1}, 1899=89210, p<0.0001\right)$. Based on the results, HIVIAIDS enlightenment campaigns disseminated through broadcast media did not have a more significant influence on adolescents' knowledge, attitudes and beliefs about HIVIAIDS than those disseminated through print media and organized activities. On the contrary, it was print media that exerted a more significant influence on adolescents' knowledge, attitudes and beliefs about HIVIAIDS than broadcast media, while organized activities had no significant influence at all.

Recall that hypothesis three stated that there will be a significant relationship between exposure to HIVIAIDS enlightenment campaign programs and sexual behaviors of adolescents, so that those in the highly exposed group would have lower sexual risk behaviours than those in the lower exposed group. Adolescents' composite scores on exposure to enlightenment campaigns were grouped into two categories, informed and highly informed, using $50^{\text {th }}$ percentile and subjected to a 2-way ANOVA. The result of the analysis, as seen in Table 3, indicate that the $F$-value for the exposure to enlightenment campaign main effect $\left(F_{1,196}=12.513, p<0.001\right)$ exceeds the tabled critical value $(F=3.84, p \leq 0.05, d f$ $\left.=1, d f_{2}=\propto\right)$.

Therefore, hypothesis three was confirmed that HIVIAIDS enlightenment campaigns had a significant influence on adolescents' sexual behaviors. A follow up pair wise comparison test between the highly informed group and informed group revealed a mean difference of 0.665 with standard error of 0.199 , which is significant at the 0.001 level. Also, there was a significant main effect of knowledge, attitudes and beliefs on adolescents' sexual behavior $\left(F_{2}, 1896=15.209, p\right.$ $<0.001$ ), but no interaction effect exist between enlightenment campaigns and knowledge, attitudes and beliefs on adolescents' sexual behavior $\left(F_{2,1896}=0.068, p=.934\right)$.

\section{Discussion}

The findings from this study revealed that all the major independent variables; exposure to enlightenment campaigns, knowledge, attitudes and beliefs about HIVIAIDS, influenced adolescents sexual behaviors.

Hypothesis one compares the influence of broadcast media with other HIVIAIDS enlightenment campaigns on adolescents' sexual behaviors. The results obtained showed that broadcast media (television and radio) had a greater influence on sexual behaviors than print media and organized activities. The finding that broadcast media, specifically radio could positively impact behavior change is consistent with Pappas-DeLuca et al. (2008) who found that radio programming was more effective in facilitating behavioral change than any other media. It is also evident from research that a multi-dimensional approach to media messaging is more successful than using a single method (Selikow, Flisher, Matthews, \& Ketye, 2006); however, this research clearly suggests that radio and television were more effective in influencing sexual behaviors than print media and other organized activities. This might be due to the fact that broadcasts media (particularly radio) was the most popular means for receiving information Keating, Meekers, \& Adewuyi, 2006; Maas \& Otte, 2009). This is followed by television, and the printed media. A study conducted by Olowosegun, Sule, Sanni, Onimisi, and Olowosegun (2010) also found that radio constituted the major source of information on HIVIAIDS; $80 \%$ of participants' source of awareness and knowledge about HIVIAIDS came from radio transmissions. Bertrand et al. (2006) conducted a review of 24 studies of the effectiveness of mass media interventions and found consistent media effects on risks reduction behaviors. 
Despite our finding, some research indicates no significant relationship between type of media exposure and behavior. Keating et al. (2006) found no significant difference between media and behavior. Bertrand et al. (2006), who conducted a systematic review of the effectiveness of certain mass communication programs, suggests that program exposure of any type had no significant impact on reported condom use at last sexual intercourse.

The results of hypothesis two shows that print media exerted significantly more influence on adolescents' knowledge, attitudes and beliefs about HIVIAIDS than did broadcast media (radio and television), while organized activities had no effect on HIV knowledge, attitudes and beliefs. This was surprising to us since we hypothesized that television and radio would have a significantly greater effect on HIVIAIDS knowledge, attitudes and beliefs than print media. One basic assumption about this discovery is that information received from print media or reading materials such as books, magazines, newspapers, posters, and billboards, had a more significant influence on people's knowledge, because it is more than mere exposure, such as is the case with broadcast media. The attention needed for print media are more concentrated and for a longer period than television featured advertisements, jingles and radio programs. These television programs may only last for a few seconds or minutes, as appose to print media which an individual can keep with them for an extended period of time. Olowosegun et al. (2010) found results inconsistent with our findings in that they discovered that radio media was more important than other mass media in enhancing knowledge of HIVIAIDS prevention. There is the tendency of going back to the materials consulted or made available in the form of leaflets, newsletter, pamphlets which provides opportunity for reappraisal and assessment of the information provided. There is the possibility that information from print media has a way of impinging on the individuals cognitive information processing based on rational objective assessments than those flickered through the television in a moment. Individual may easily forget what they see or hear in seconds but internalize more of what they take time to read, digest and assimilate (Selikow et al., 2006).

Prior research has observed that television programs and advertisement (both free and paid- for media coverage) have been the main sources of AIDS information for all age groups (Khosrovani, Desai, \& Sanders, 2011). As noted in the literature review, leaflets and the print media are secondary sources of information, while family and friends are very much a subsidiary source.

On the third hypothesis, it was discovered that a significant relationship exists between adolescents' exposure to enlightenment campaigns and sexual behavior but not in the expected direction. It was expected that adolescents that were more exposed to all forms of HIVIAIDS enlightenment campaigns would be cautious and engage in less sexual risk activities, than those exposed to less enlightenment campaigns, however the result obtained revealed the opposite. The highly exposed adolescents took more sexual risk than the exposed group. Davis, Sloan, MacMaster and Kilbourne (2007) support our finding on exposure to enlightenment campaign, which revealed that adolescents' knowledge about sex does not always match their behavior. This study observed that sexuality education programs increase knowledge about sexuality, but there is little evidence that they change attitudes or behaviors. The finding is also consistent with Kirby's (2008) evaluation study of abstinence education programs, which provided strong evidence that some abstinence programs are ineffective and have little to no affect on adolescents' sexual behavior.

Some research has suggested that individuals are more likely to change as a result of the discussion of campaigns rather than as a direct result of messaging itself (Noar, 2006). This result is also in line with Coates, Richter, and Caceres (2008) who confirmed that behavior modification is best achieved by small peer group sessions and community based approaches rather than large scale campaigns, which produce marginal changes that are difficult to sustain. Zeelen, Wijbenga, Vintges, and Jong (2010) reported adoption of old traditions of storytelling and youth literature as a new methods of AIDS education among South African youths based on findings that mass education focused approaches are not inclusive enough to break with cultural stereotypes. This is consistent with Bertrand et al. (2006) who observed that a substantial body of communication literature based on experience in developed countries has shown that the majority of mass media campaigns have no statistically significant impact on behavior change.

Despite our findings, some studies have found adolescent behavioral change to be possible through the use of enlightenment/awareness campaigns. Shimbuli, Oyedokun, and McNally (2009), conducted a study to determine the effectiveness of an awareness campaign directed toward students of the Polytechnic of Namibia. Results of the analysis indicated that the awareness campaign had a positive effect on the participants' knowledge, attitude, belief, behavior change and sexual practices.

Kirby and Laris (2009) also reported on sex education program delivered to high school students, finding that the majority of curriculum-based sex and STD/HIV education programs have a significant positive impact on behavior; including increased knowledge about HIV and STD's and increased communication with parents. Selikow et al. (2006) suggests a similar idea, that mass media campaigns alone cannot facilitate behavior change among adolescents, but 
that a multipronged approach to media, theory led initiatives of behavior change, dealing with multiple sources of conflicting information, and challenging traditional ideas of masculinity and femininity all play a role in ensuring the effectiveness of HIVIAIDS enlightenment campaigns.

\section{References}

Anema, A., Freifeld, C. C., Druyts, E., Montaner, J. S. G., Hogg, R. S., \& Brownstein, J. S. (2010). An assessment of global internetbased HIVIAIDS media coverage: implications for United Nations programme on HIVIAIDS' global media HIVIAIDS initiative. International Journal of STD \& AIDs, 21(1), 26-29.

Bertrand, J.T., K. O'Reilly, J. Denison, R. Anhang, \& M. Sweat. 2006. Systematic review of the effectiveness of mass communication programs to change HIVIAIDS-related behaviors in developing countries. Health Education Research, 21:567-597.

Cherutich, P., Brentlinger, P., Nduati, R., Kiarie, J., \& Farquhar, C. (2008). Condom use among sexually active Kenyan female adolescents at risk for HIV-1 infection. AIDS and Behavior, 12(6), 923-929.

Coates, T. J., Richter, L., \& Caceres, C. (2008). Behavioural strategies to reduce HIV transmission: how to make them work better. Lancet, 372(9639), 699-684

Davis, C., Sloan, M., MacMaster, S., \& Kilbourne, B. (2007). HIVIAIDS knowledge and sexual activity: an examination of racial differences in a college sample. Health Social Work, 32(3), 211-218

Hallet, T. B., Lewis, J. J., Lopman, B. A., Nyamukapa, C. A., Mushati, P., Wambe, M.,... Gregson, S. (2007). Age at first sex and HIV infection in rural Zimbabwe. Studies in Family Planning, 38(1), 1-10

Jemmott, J. B. (2012). The reasoned action approach in HIV risk-reduction strategies for adolescents. The ANNALS of the American Academy of Political and Social Science, 640(1), 150-172.

Kalichman, S. C., Ntseane, D., Nthomang, K., Segwabe, M., Phorano, O., \& Simbayi, L. C. (2007). Recent multiple sexual partners and HIV transmission risks among people living with HIVIAIDS in Botswana. Sexually Transmitted Infections, 83(5), 371-375.

Keating, J., Meekers, D., Adewuyi, A. (2006). Assessing effects of a media campaign on HIVIAIDS awareness and prevention in Nigeria. BMC Public Health, 6(123), 1-12.

Khosrovani, M., Desai, M. S., Sanders, A. (2011). African American college students opinions of media messages on HIVIAIDS awareness: students' attitudes toward the disease. College Student Journal, 45(2), 414-427

Kirby, D. (2008). The impact of abstinence and comprehensive sex and STD/HIV education programs on adolescent sexual behavior. Sexuality Research and Social Policy, 5(3), 18-27

Kirby, D. \& Laris, B. A. (2009). Effective curriculum-based sex and STD/HIV education programs for adolescents. Child Development Perspectives, 3(1), 21-29.

Kirby, D., Laris, B. A., \& Rolleri, L. Impact of sex and HIV education programs on sexual behaviors of youth in developing and developed countries: FHI youth research working paper no 2. North Carolina: Family Health International (Youth Net Program), 2009

Kurth, A. E., Celum, C., Baeten, J. M., Vermund S. H., \& Wasserheit, J. N. (2011). Combination HIV prevention: significance, challenges, and opportunities. Current HIV/AIDS Reports, 8(1), 62-72.

Li, S., Huang, H., Cai, Y., Ye, X., Shen, X., Shi, R., \& Xu, G. (2010) Evaluation of a schoolbased HIVIAIDS peer-led prevention programme: the first intervention trial for children of migrant workers in China. International Journal of STD \& AIDS, 21(2), 82-86.

Ma, Q., Ono-Kihara, M., Cong, L., Xu, G., Pan, X., Zamani, S.,...Kihara, M. (2009). Early initiation of sexual activity: A risk factor for sexually transmitted diseases, HIV infection, and unwanted pregnancy among university students in China. BMC Public Health, 9(111), 1-8.

Marshall, K., Crepaz, N., \& O'Leary, A. (2010). A systematic review of evidence-based behavioral interventions for African American youth at risk for HIVISTI infection, 1988-2007. In D. H. McCree, K. T. Jones, \& A. O'Leary (Eds.), African Americans and HIVIAIDS: Understanding and addressing the epidemic (pp. 151-180). New York, NY: Springer.

Maas, F. V. D., \& Otte, W. (2009). Evaluation of HIVIAIDS secondary school peer education in rural Nigeria. Health Education Research, 24(4), 547-557.

Medley, K. D., Kennedy, C., O'Reilly, K., \& Sweat, M. (2009). Effectiveness of peer education interventions for HIV prevention in developing countries: a systematic review and meta-analysis. AIDS Education and Prevention, 21(3), 181-206.

Menser, M. (2010). Perceived risk, decisional balance, and HIV testing practices in college students. (Master's Thesis, University of Pittsburgh). Retrieved from http://d-scholarship.pitt.edu/6934/

Myers J. J., Shade, S.B., Rose, C.D., Koester, K., Maiorana, A., Malitz, F.E.,... Morin, S. F. (2010). Interventions delivered in clinical settings are effective in reducing risk of HIV transmission among people living with HIV: results from the Health Resources and Services Administration (HRSA)'s Special Projects of National Significance initiative. AIDS Behavior 14(3), 483-492.

Noar, S. M. (2006). A 10-year retrospective of research in health mass media campaigns: Where do we go from here? Journal of Health Communication, 11(1), 21-42.

Olowosegun, T., Sule, A. M., Sanni, O. A., Onimisi, H. U., \& Olowosegun, O. M. (2010). Awareness of HIVIAIDS pandemic in selected fishing communities in North Central Nigeria. Asian Journal of Epidemiology, 3, 100-106.

Pappas-DeLuca, K. A., Kraft, J., Galavotti, C., Warner, G. L., Mooki, M., Hastings, P.,....Kilmarx, P. H. (2008). Entertainment-education radio serial drama and outcomes related to HIV testing in Botswana. AIDS Education and Prevention, 20(6), 486-503

Robbins, C. L., Zapata, L., Kissin, D. M., Shevchenko, N., Yorick, R., Skipalska, H.,... Hillis, S. D. (2010). Multicity HIV seroprevalence 
in street youth, Ukraine. International Journal of STD \& AIDs, 21(7), 489-496

Sandfort, T. G. M., Orr, M., Hirsch, J. S., \& Santelli, J. (2008). Long-term health correlates of timing of sexual debut: results from a national US study. American Journal of Public Health, 98(1), 155-161.

Selikow, T., Flisher, A. J., Matthews, C., \& Ketye, T. (2006). Media messaging: a synthesis of lessons from the literature to inform HIV prevention amongst young people. Journal of Child and Adolescent Mental Health, 18(2): 61-72

Shelton, J. (2009). Why multiple sexual partners? The Lancet, 374(9687), 367-369.

Shimbuli, F., Oyedokun, C., \& McNally, A. (2009). The impact of the HIVIAIDS awareness campaign on knowledge, attitudes, beliefs, sexual behaviour change and confidence in sexual practices. Nawa Journal of Language and Communication, 3(1), 81-100

Wakefield, M. A., Loken, B., \& Hornik, R. C. (2010). Use of mass media campaigns to change health behavior. The Lancet, 376(9748), 1261-1271

World Health Organization. 2008. HIV AIDS epidemic update. World Health Organization, Geneva, Switzerland.

Zeelen, J., Wijbenga, H., Vintges, M., \& Jong, G. (2010). Beyond silence and rumor: storytelling as an educational tool to reduce the stigma around HIVIAIDS in South Africa. Health Education,110(5), 382 - 398.

\section{Apendix}

Table 1: Multiple Regression Analysis on the Influence of HIVIAIDS Enlightenment Campaign on Adolescents Sexual Behaviors

\begin{tabular}{|c|c|c|c|c|c|c|}
\hline \multicolumn{7}{|c|}{ Variables (s) Entered on stepwise method. } \\
\hline 1 & \multicolumn{6}{|c|}{ BRODMED - Broadcast media } \\
\hline 2. & \multicolumn{6}{|c|}{ PRITMED - Print media. } \\
\hline 3. & \multicolumn{6}{|c|}{ PRGACTV - Organised activities. } \\
\hline Multiple R & - & \multicolumn{5}{|l|}{0.227} \\
\hline R SQuare - & \multicolumn{6}{|l|}{0.052} \\
\hline Adjusted R & - & \multicolumn{5}{|l|}{0.05} \\
\hline \multicolumn{7}{|c|}{ Variables in the Equation } \\
\hline Variable & & B & SE B & Beta & $\mathrm{T}$ & Sig. $T$ \\
\hline Brodmed & & 0.357 & 0.041 & 0.217 & 8.769 & 0.0001 \\
\hline Printmed & & -0.262 & 0.053 & -0.120 & -4.980 & 0.0001 \\
\hline Orgactv & & 0.110 & 0.048 & 0.056 & 2.310 & 0.021 \\
\hline Constant & & 14.726 & 1.150 & - & 12.810 & 0.0001 \\
\hline
\end{tabular}

Table 2: Multiple Regression Analysis on the Influence of Three Methods of HIVIAIDS enlightenment campaign on Adolescents' Knowledge, Attitudes and Beliefs about HIVIAIDS.

\begin{tabular}{|c|c|c|c|c|c|}
\hline \multicolumn{6}{|c|}{ Variables (s) entered on stepwise method. } \\
\hline 1. & BRODMED - & Broadcast media & & & \\
\hline 2. & PRITMED & Print media. & & & \\
\hline \multirow[t]{5}{*}{3.} & ORGANCTV - & Organised activities. & & & \\
\hline & Multiple R & 0.232 & & & \\
\hline & R square & 0.054 & & & \\
\hline & Adjusted R square & 0.053 & & & \\
\hline & Standard Error & 2.272 & & & \\
\hline \multicolumn{6}{|c|}{ Variables in the Equation } \\
\hline Variable & B & SE.B & Beta & $\mathrm{T}$ & Sig. $T$ \\
\hline Pritmed & 0.295 & 0.028 & 0.246 & 10.358 & 0.0001 \\
\hline Brodmed & $-9.108 \mathrm{E}-02$ & 0.022 & -0.100 & -4.233 & 0.0001 \\
\hline Constant & 24.121 & 0.614 & - & 39.281 & 0.0001 \\
\hline
\end{tabular}

Table 3: Influence of Enlightenment Campaigns and Knowledge, Attitudes and Beliefs on Adolescents' Sexual Behaviors

\begin{tabular}{|c|c|c|c|c|c|}
\hline \multicolumn{6}{|c|}{ Dependent Variable: (sexual behavior) } \\
\hline Source & Type III Sum of Squares & df & Mean Square & $\mathbf{F}$ & Sig. \\
\hline Corrected Model & 766.602 & 5 & 153.320 & 9.312 & .000 \\
\hline Intercept & 709047.914 & 1 & 709047.914 & 43065.422 & .000 \\
\hline Enlightenment & 206.016 & 1 & 206.016 & 12.513 & .000 \\
\hline Knowledge, attitudes and beliefs(KAB) & 500.807 & 2 & 250.403 & 15.209 & .000 \\
\hline Enlightenment * $\mathrm{KAB}$ & 2.239 & 2 & 1.120 & .068 & .934 \\
\hline Error & 31216.572 & 1896 & 16.464 & & \\
\hline Total & 859189.881 & 1902 & & & \\
\hline Corrected Total & 31983.174 & 1901 & & & \\
\hline
\end{tabular}


ISSN 2239-978X

ISSN 2240-0524
Journal of Educational and Social Research MCSER Publishing, Rome-Italy
Vol. 4 No. 6 September 2014 